\title{
A new type of lordosis and vertebral body compression in Gilthead sea bream, Sparus aurata L.: aetiology, anatomy and consequences for survival
}

\author{
M Loizides ${ }^{1}$, A N Georgiou ${ }^{1,2}$, S Somarakis ${ }^{3}$, P E Witten ${ }^{4,5}$ and G Koumoundouros ${ }^{1}$ \\ 1 Biology Department, University of Crete, Vasilica Vouton, Heraklio, Crete, Greece \\ 2 Biology Department, University of Patras, Rio, Patras, Greece \\ 3 Institute of Marine Biological Resources, Hellenic Centre for Marine Research, Thalassocosmos, Heraklion, Crete, \\ Greece \\ 4 Evolutionary Developmental Biology, Biology Department, Ghent University, Ghent, Belgium \\ 5 Institute of Veterinary Animal and Biomedical Science, Massey University, Palmerston North, New Zealand
}

\section{Abstract}

A new type of vertebral malformation is described, consisting of deformed cartilaginous neural and haemal processes and the compression and fusion of vertebral bodies. The malformation is designated as haemal vertebral compression and fusion (haemal VCF). We studied the aetiology of the malformations and described microanatomical histopathological alterations. The malformations were detected during routine quality control in one of six monitored Gilthead sea bream populations. Haemal VCF affected the posterior part of the vertebral column (haemal vertebrae). In $20 \%$ of the deformed specimens, haemal VCF was combined with lordosis. At $35 \mathrm{dph}$ (days posthatching), early anatomical signs of the haemal VCF consisted of abnormal centrum mineralization, malformed cartilaginous neural and haemal processes and developing lordotic alterations. The histological examination of the deformed individuals revealed that haemal VCF is preceded by notochord abnormalities. The frequency of deformed individuals was three times higher at 35 than at $61 \mathrm{dph}(50.3 \%$ vs. $17.2 \%, n=157$ and $n=250$, respectively). No signs of repair or reversion of malformations have been observed. Thus, the steep decrease in deformities in older

Correspondence G Koumoundouros, Biology Department, University of Crete, Vasilica Vouton, 70013 Heraklio, Crete, Greece (e-mail: gkoumound@biology.uoc.gr) animals suggests that haemal VCF is linked to high mortality rates. The results are discussed in respect of the possible causative factors of haemal VCF.

Keywords: skeletal deformities, notochord abnormalities, fish larvae.

\section{Introduction}

Skeletal deformities are a major problem for marine finfish aquaculture, affecting survival, animal welfare and product quality (reviewed by Koumoundouros 2010; Boglione \& Costa 2011; Cobcroft \& Battaglene 2013). Although of lower frequency in the wild, skeletal deformities have been reported to develop in various fish populations and have been suggested as significant indicators of environmental disturbances and pollution (Boglione et al. 2006; Koumoundouros 2008; Diggles 2013).

Concerning Mediterranean finfish aquaculture, data from commercial hatcheries report mean frequencies of skeletal deformities that reached from 7 to $20 \%$ during the last decade, for a total annual production of approximately one billion juveniles (Koumoundouros 2010). In advanced teleost fish, skeletal deformities develop especially in early life stages, during the larval rearing phase. Early malformations are believed to be linked to suboptimal levels of a variety of abiotic (Polo, 
Yufera \& Pascual 1991; Sfakianakis et al. 2006; Georgakopoulou et al. 2007, 2010; Cobcroft \& Battaglene 2009) and nutritional factors (Fernandez et al. 2008; Mazurais et al. 2009; Darias et al. 2010). In hatcheries, skeletal deformities develop due to gaps of knowledge about factors that are required to facilitate healthy skeletal development. Our knowledge is increasing (Boglione, Gavaia, Koumoundouros, Gisbert, Moren, Fontagné \& Witten 2013a; Boglione et al. 2013b; Izquierdo et al. 2013), but uncontrolled fluctuations of various parameters in the complex larval rearing systems can still cause early skeletal malformations. A prerequisite for achieving healthy skeletal development is the early diagnosis of malformations, a precise diagnosis of the pathological processes and consequently the identification of the optimal rearing conditions for different species. Establishing procedures for early diagnosis will also help to improve quality monitoring in commercial hatcheries (Koumoundouros 2010).

Part of the solution relies on studies about the ontogeny, anatomy and aetiology of skeletal deformities. Such studies have been suggested to be significant for the effective hypothesis formation and experimental testing of the responsible causative factors, as well as for quality monitoring in hatcheries (Koumoundouros 2010; Boglione et al. 2013b). In the present study, we analyse a new type of vertebral deformities in Gilthead sea bream, Sparus aurata L.

\section{Materials and methods}

Fish samples were derived from a commercial hatchery and were obtained in the frame of routine quality control in 2011. Random samples of 150-350 larvae were taken from six different sea bream populations at the age of 35 and $61 \mathrm{dph}$ (days post-hatching). The animals were anaesthetized, fixed in 5\% phosphate-buffered formalin and subsequently stained for bone and cartilage (Walker \& Kimmel 2007). All stained specimens were individually photographed and examined for the presence of skeletal deformities. The terminology used to describe malformations followed Koumoundouros (2010). Staging of vertebral column development followed Faustino \& Power (1998) (Fig. 1). Recording of vertebral deformities provided data about the location of anteriormost and posteriormost deformed vertebrae, the vertebra located at the centre of the deformity, as well as about the total number of deformed vertebrae. Numbering of vertebrae followed a caudad direction. The standard length (SL, tip of snout to the base of middle caudal ray) and the head length (HL, tip of snout to the posterior margin of operculum) of each specimen were measured by means of tpsDig2 software (Rohlf 2008). Head length was chosen as an additional measure of body size, because vertebral deformities can significantly affect the length of the vertebral column and thus the standard length of the specimens (Witten et al. 2006).

For the histological examination of the deformed vertebral columns, two specimens stained for bone and cartilage $(35 \mathrm{dph})$ were embedded in glycol methacrylate (Technovit 7100, Heraeus Kulzer). Serial parasagittal semithin sections $(2 \mu \mathrm{m})$ were subjected to metachromatic staining for proteoglycans (cartilage and notochord sheath) with a solution of $0.25 \%$ toluidine blue and $1 \%$ sodium tetraborate. The sections were mounted with DPX (Fluka). To precisely identify the areas of malformation on the tissue level, complete slides with the serial sections of the fish were scanned at $4000 \mathrm{dpi}$ (Polaroid Sprint Scan 120) and aligned with the photographs of the whole-mount-stained individuals. Tissues were

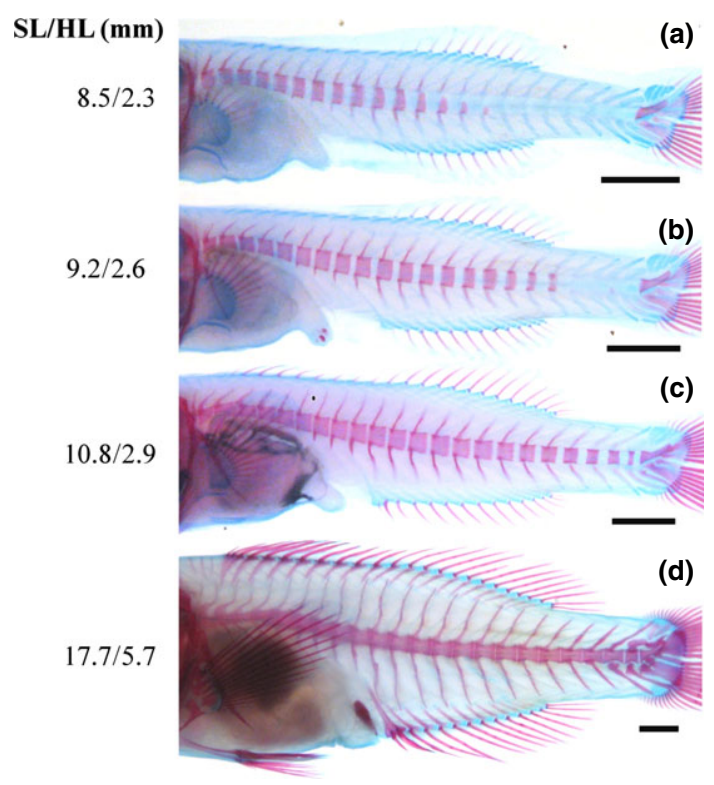

Figure 1 Normal ontogenetic pattern of the haemal vertebrae in S. aurata. The development of cartilaginous neural and haemal processes precedes that of vertebral centra. Vertebral centra anlagen arise by mineralization of the notochord sheath. SL, standard length. HL, head length. Scale bars equal to $1 \mathrm{~mm}$. 
subsequently analysed with a Carl Zeiss Axio Imager $\mathrm{Z}$ microscope.

All the six examined fish populations were reared simultaneously in the facilities of the commercial hatchery, according to the standard methodology for the intensive larval rearing of sea bream. The populations were established from eggs that were obtained from the same broodstock during two sequential spawns (three populations from each spawn). In short, the autotrophic and larval phases were performed in indoor tanks of $12 \mathrm{~m}^{3}$ at an initial stocking density of 100 ind $\mathrm{L}^{-1}$. Larvae were reared in the presence of background phytoplankton (Chlorella sp.), with initial feeding on enriched rotifers (5-30 dph), followed by gradual provision of Artemia instar I (19-24 dph) and enriched instar II nauplii (22-45 dph) and finally of inert commercial diets $(>30 \mathrm{dph})$. During the entire rearing phase, the tanks were supplied with borehole sea water. Water temperature was $19.0-20.5^{\circ} \mathrm{C}$, salinity was $35 \mathrm{~g} \mathrm{~L}^{-1}$ and oxygen saturation was $90-95 \%$.

Mann-Whitney U statistic was used to test the significance of the differences in the meristic characters between different samples. G-test was used to compare the frequency of the deformities between different samples (Sokal \& Rohlf 1981).

\section{Results}

One of the six examined populations presented an unusual high frequency of vertebral deformities, ranging from $50.3 \%$ at $35 \mathrm{dph}$ (79 of 157 fish) to $17.2 \%$ at $61 \mathrm{dph}$ (43 of 250 fish). Deformities were present at the haemal part of the vertebral column. The most frequently observed pathology was an extensive vertebral compression and fusion (VCF, $80 \%$ of the deformed specimens) (Fig. $2 \mathrm{~d}-$ g). Of the individuals with deformed vertebral bodies, 20\% also displayed severe lordosis (Fig. 3d-g). The examination of the $35 \mathrm{dph}$ sample revealed that the early anatomical signs of the VCF type were evident in the form of abnormal pattern of centrum development (Fig. $2 \mathrm{a}-\mathrm{c}$ ) and of condensed developmental pattern of vertebral processes (Fig. 2b, c). In the case of vertebral lordosis, early anatomical signs also included a V-shaped curvature of the notochord, associated with abnormally shaped cartilaginous anlagen of the haemal and neural processes (Fig. $3 \mathrm{a}-\mathrm{C}$ ).

On average, deformities developed anterior and posterior to the 17 th-18th vertebral centrum anlage and consisted of 8-9 deformed and fused vertebrae. No significant differences were detected in the meristic characters of the deformed area between the samples at 35 and $61 \mathrm{dph}$ (Table 1). Similarly, in the one population affected, no significant differences between the two samples were detected with respect to the relative frequency of the two types of vertebral deformities (Fig. 4).

The vertebral column of animals of about $8 \mathrm{~mm}$ SL (Fig. 2a-c and Fig. 5a) consisted of a still unconstricted notochord (Fig. 5a'). Highly vacuolated notochord cells are located in the centre of the notochord, and a typical notochord epithelium is located at its periphery (Fig. 5a", b). The notochord epithelium is surrounded by a typical notochord sheath and the elastic membrane (Fig. 5b, d). In non-deformed vertebral bodies, the deposition of bone matrix onto the notochord sheath has started, but complete bony vertebral bodies have not been formed (Fig. 5b). Mineralized vertebral bodies, as seen in wholemount-stained specimens (Fig. 2), are still based on the mineralization of the notochord sheath (Fig. 5a'). In intervertebral spaces, cells of the notochord epithelium accumulate and secrete a thickening non-mineralized notochord sheath (Fig. 5c).

At the locations of malformations (Fig. 5a"'), the cellular structure of the notochord was altered. Instead of vacuolated notochord cells in the centre of the notochord, the lumen of the notochord was filled with cells that contain only small or no vacuoles. Different from the highly vacuolated cells of a normal notochord lumen, cell nuclei were prominent (Fig. 5a'", e, 5G). The notochord epithelium appeared to be proliferative, and there was an apparent increased secretion of notochord sheath material (Fig. 5e, f). Cells could obtain chondroid-like morphology (Jonasson, Russell \& Vickaryous 2012) and produce a matrix that stained metachromatically, similar to cartilage-like matrix (Fig. 5f). The thickness of the notochord sheath in the area with malformation was highly variable (Fig. 5e, h). Caudad to the malformed area, a disruption of the notochord sheath was observed (Fig. 5h).

The above-described deformities were observed in only one of the six populations that were examined during routine quality control. A total of $1-3 \%$ of jaw and operculum deformities were identified in all the six examined populations. 
(a)
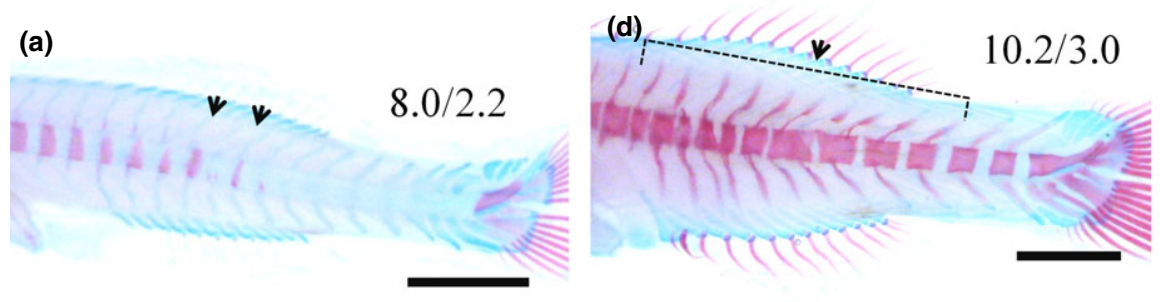

(b)
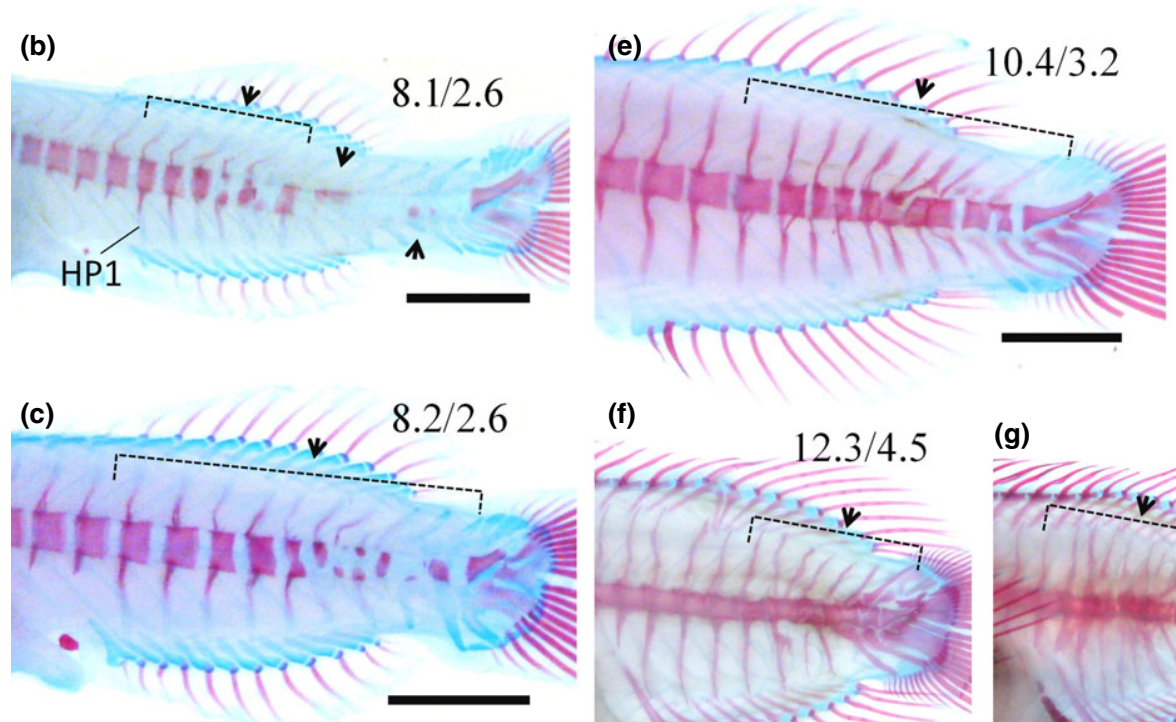

(f)
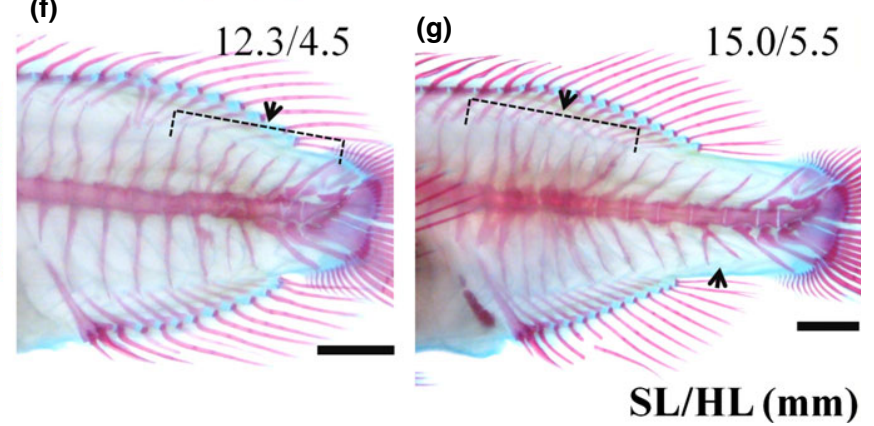

Figure 2 Anatomy of vertebral compression in different ontogenetic phases of S. aurata. (a) Abnormal sequence of centra mineralization, with two haemal centra (arrows) presenting a higher degree of mineralization than anterior located centra. (b, c) Abnormal pattern of centra development (arrows), with mineralization defects and clearly deformed haemal and neural processes. (d, e) Compression and fusion of haemal vertebrae (arrow) with mineralization defects. (f, g) Fusion of compressed vertebrae (arrows) at later stages of development.

\section{Discussion}

In Mediterranean aquaculture, various types of severe vertebral deformities have been identified. These deformities can reach a high frequency and are thus of major significance for hatcheries (Boglione et al. 2013b). Following previous studies, this group of significant deformities includes the prehaemal lordosis (Chatain 1994), haemal lordosis (Divanach et al. 1997; Sfakianakis et al. 2006; Georgakopoulou et al. 2010) and the prehaemal kyphosis (Koumoundouros et al. 2002). The compression and fusion of two to three adjacent vertebrae is a frequently recorded deformity in reared Gilthead sea bream (up to 14.29\%, Boglione et al. 2001). These fusions can affect all regions of the vertebral column without an apparent specific location within the spine (Boglione et al. 2001). In the present study, a new type of vertebral compression and fusion (VCF) is described to affect exclusively the haemal part of the vertebral column. We designated this pathology as 'haemal VCF' and presented evidence that it is the ontogenetic result of notochord abnormalities and of subsequent alterations of the vertebral developmental pattern. Similar to prehaemal kyphosis in European sea bass (Koumoundouros et al. 2002), the frequency of haemal VCF significantly decreased during ontogeny (from 50.3 to $17.2 \%$ ). This suggests a high mortality rate in individuals that suffer from haemal VCF. The increasing severity of the haemal VCF during ontogeny indicates that the recovery of deformed vertebral body anlagen into normal vertebrae, as has been observed in Atlantic 

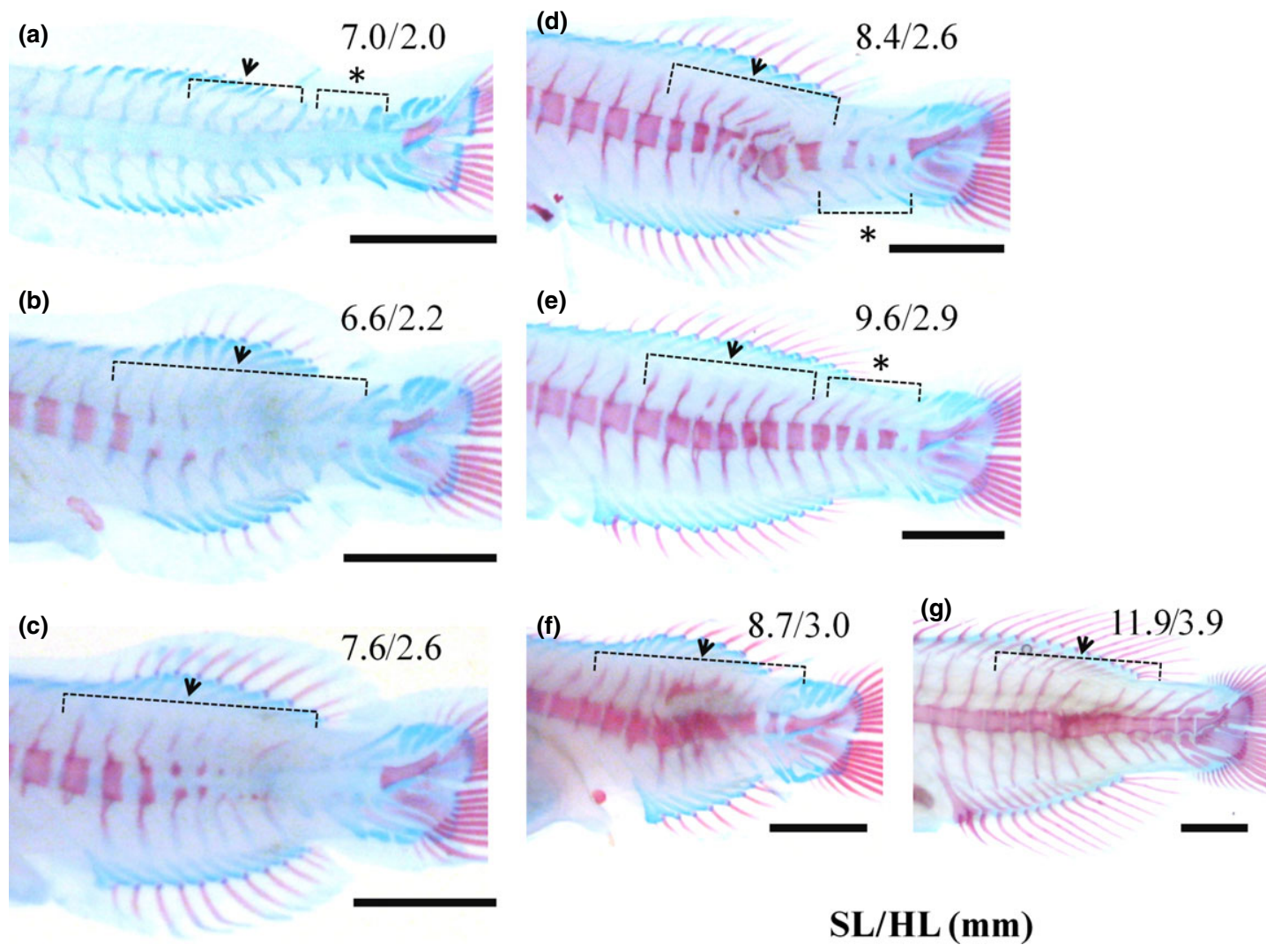

Figure 3 Anatomy of VCF-related haemal lordosis in different ontogenetic phases of S. aurata. (a) Early signs of notochord lordosis (arrow), combined with compressed vertebral processes $(*)$. Malformed vertebral processes are also present in the lordotic area. (b, c) Abnormal pattern of vertebral development, combined with haemal lordosis (arrow). (d, e) Notochord lordosis (arrow), combined with distorted and compressed vertebral centra $(*)$. Malformed vertebral processes are also present in the lordotic area. (f, g) At the later ontogenetic stages, abnormal vertebrae fuse together (arrow).

Table 1 Vertebra (position number) located at the anterior, at the posterior and at the centre of the deformed area. The total number of deformed vertebrae is also given. Values correspond to mean $\pm \mathrm{SD}$

\begin{tabular}{|c|c|c|c|c|c|}
\hline \multirow[b]{2}{*}{ Age } & \multicolumn{3}{|c|}{ Vertebra position (caudad numbering) } & \multirow[b]{2}{*}{ Total affected } & \multirow[b]{2}{*}{$n$} \\
\hline & Anterior Vertebra & Posterior Vertebra & Vertebra at Deformity Centre & & \\
\hline $35 \mathrm{dph}$ & $13.2 \pm 3.2$ & $20.8 \pm 3.2$ & $17.1 \pm 2.8$ & $8.3 \pm 3.9$ & 79 \\
\hline $61 \mathrm{dph}$ & $14.2 \pm 3.1$ & $22.0 \pm 1.8$ & $18.0 \pm 2.3$ & $8.8 \pm 3.4$ & 43 \\
\hline
\end{tabular}

$n$, number of deformed specimens examined.

salmon (Witten et al. 2006), appears to be not possible in the present study.

In almost $20 \%$ of the deformed specimens, haemal VCF was accompanied by lordosis (present paper). Existing literature on haemal lordosis shows that it is induced during the post-metamorphosis phase, primarily due to the intense swimming effort of fish (Divanach et al. 1997; Kihara et al. 2002; Sfakianakis et al. 2006). Other factors that have been associated with haemal lordosis are inadequate levels of vitamin A during the larval phase (Mazurais et al. 2009), unfavourable temperature during the embryonic, larval and juvenile phase (Sfakianakis et al. 2006; Georgakopoulou et al. 2010), and mutations (Gorman et al. 2012). In contrast to the previously described haemal lordosis where vertebral fusion-related bone alterations are a secondary event (Kranenbarg et al. 2005), VCF-related haemal lordosis was linked to primary vertebral fusions that started in the 


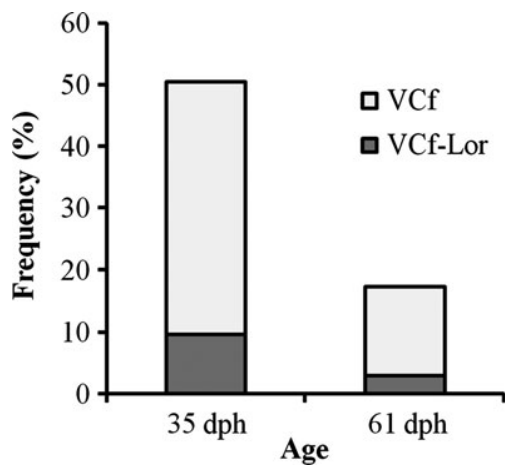

Figure 4 Frequency of deformed individuals at the age of $35 \mathrm{dph}(9.6 \pm 1.3 \mathrm{~mm} \mathrm{SL})$ and $61 \mathrm{dph}(18.8 \pm 1.9 \mathrm{~mm}$ SL). VCF, vertebral compression and fusion. VCF-Lor, VCFrelated lordosis. $n=157$ and $n=250$ for $35 \mathrm{dph}$ and $61 \mathrm{dph}$, respectively.

mineralized notochord sheath, well before the development of bony vertebral centra (present study).

Notochord abnormalities have been frequently reported to develop in early life stages of fish, due to the action of a variety of factors such as water pollution (Zhou et al. 2009), unfavourable temperature (Polo et al. 1991) and mechanical forces due to swim bladder overinflation (Grotmol, Kryvi \& Totland 2005). Under aquaculture conditions, notochord abnormalities that appear during the early larval stage are often connected to high mortality rates (Barahona-Fernandes 1982; Andrades, Becerra \& Fernandez-Llebrez 1996). Here, we observe that alterations of the notochord co-localize with vertebral body malformations. In teleost fish, as in other vertebrates (e.g. humans), a healthy notochord is a lifelong prerequisite to prevent malformations of the vertebral column (Witten et al. 2005; Risbud \& Shapiro 2011). At the examined stages of development, vertebral bodies of teleosts consist of the mineralized notochord sheath (Huxley 1859; Bensimon-Brito et al. 2012a), initially without the contribution of bone or bone forming cells (Renn \& Winkler 2012). Consequently, malformed vertebral body anlagen represent mineralization defects of the notochord sheath as has been shown for medaka (Oryzias latipes) under experimental conditions (Willems et al. 2012). Alterations of the notochord that are linked to vertebral column malformations have also been described for sea bream larvae by Santamaria et al. (1994) and Andrades et al. (1996) and for juvenile sea bream by Fernández et al.
(2012). A possible cause for the observed mineralization defects is the ectopic presence of altered notochord cells and the increased production of notochord sheath. Increased ectopic production of notochord sheath matrix likely prevents mineralization of the notochord sheath. Increased notochord sheath production occurs under regular conditions in prospective intervertebral spaces, sites where mineralization is inhibited through unknown mechanisms (Bensimon-Brito et al. 2012b; Fjelldal et al. 2012). In the present study, we also observed disruption of the notochord sheath. Possibly, this disruption can trigger the alteration of the notochord tissue, as it has been recently described for medaka (To et al. 2012). Despite evidence that early vertebral body formation is notochord related (Hall 1977; De Azevedo et al. 2012; Willems et al. 2012), it is also known that notochord sheath mineralization starts at the insertion point of the cartilaginous arches to the notochord (Hay 1895; Schultze \& Arratia 1988). Consequently, a disturbance of arch formation could precede the disruption of notochord mineralization. Still, the fact that we have not observed alterations of the cartilage structures but observed severe alterations of notochord tissue argues for initially notochord-based pathology.

In the present study, the deformity of the haemal vertebrae was detected in only one of the six simultaneously reared populations. No VCF deformity was detected in any of the rest 34 sea bream populations that were reared during 2011 in the same hatchery (data not shown). Therefore, although the deformity affected half of the larvae (at $35 \mathrm{dph}$ ) of a single population, it cannot currently be considered as a frequent deformity. Moreover, the low incidence of affected populations (1/40 in total for 2011) in the same hatchery clearly demonstrates that standard rearing methodology followed by the hatchery should not be considered as the cause of VCF deformities. As a possible cause, we could suggest a 'random' methodological alteration (e.g. fast temperature acclimation and wrong set-up of aeration or of surface skimmer) that acted during the early ontogeny (embryonic and yolk-sac larval stage). The results of the present study clearly underline the importance of early quality control at various phases of the hatchery period for the early termination of the rearing of populations that in the next stages will present a high frequency of skeletal deformities or deformity-induced high 

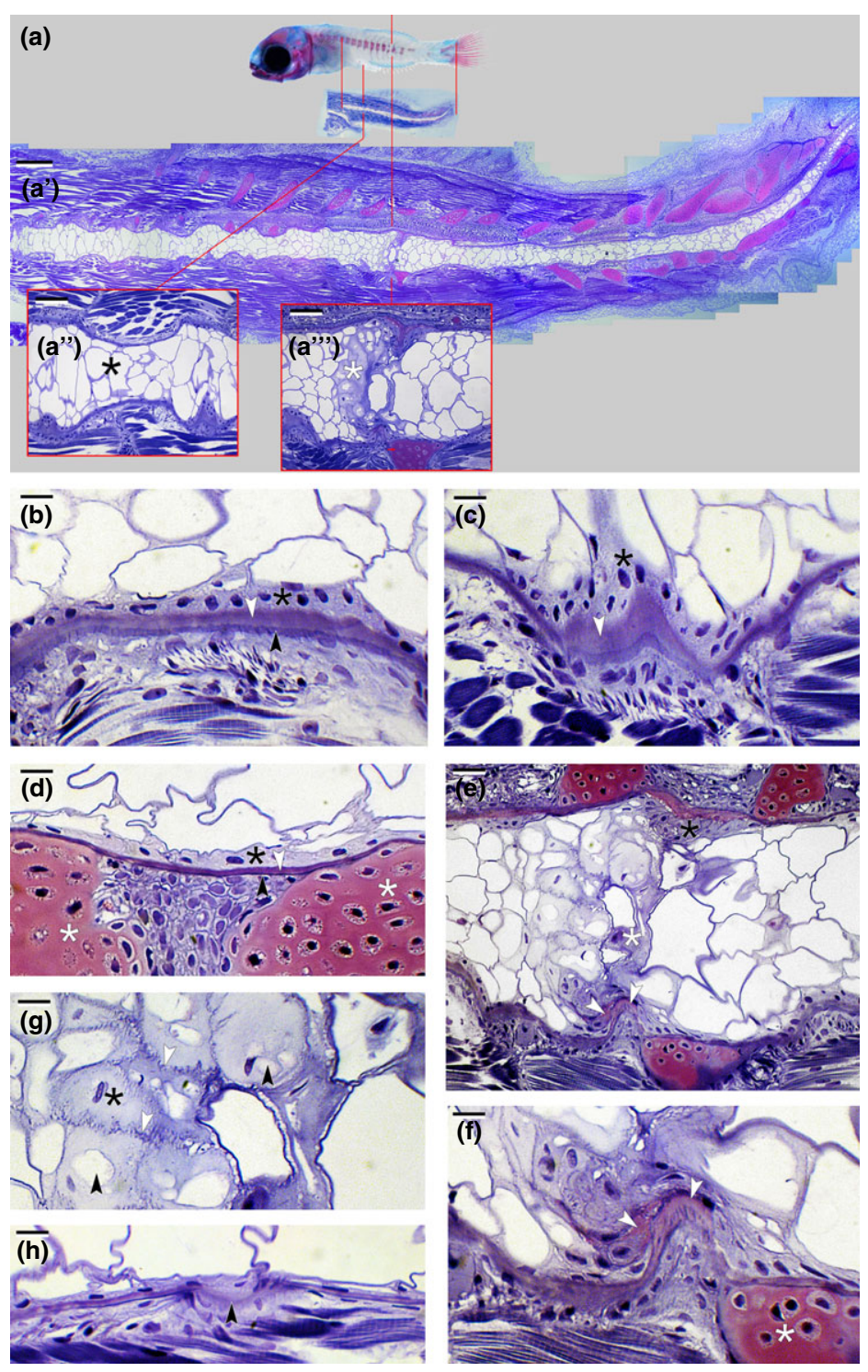

Figure 5 (a) Sagittal sections through the developing vertebral column of a previously whole-mount-stained larva $(35 \mathrm{dph}, 8.1 \mathrm{~mm}$ $\mathrm{SL}, 2.6 \mathrm{~mm} \mathrm{HL}$ ) with malformed vertebral bodies in the caudal region. ( $\left.\mathrm{a}^{\prime}\right)$ Alignment of the whole-mount-stained specimen with the histological section (scale bar $=250 \mu \mathrm{m})$. ( $\left.\mathrm{a}^{\prime \prime}\right)$ Regular notochord tissue (black asterisk) in the non-altered abdominal region of the spine (scale bar $=30 \mu \mathrm{m}) .\left(\mathrm{a}^{\prime \prime \prime}\right)$ Altered notochord tissue (white asterisk) in the region of spine malformation (scale bar $\left.=30 \mu \mathrm{m}\right)$. (b) higher magnification of the non-altered notochord epithelium (black asterisk) and the notochord sheath (white arrowhead) in the region indicated by Fig a'. Outside the notochord sheath, a thin layer of bone matrix is visible (black arrowhead), presumably not yet mineralized (scale bar $=10 \mu \mathrm{m}$ ). (c) Accumulation of notochord sheath cells (black asterisk) and increased thickness of the notochord sheath (white arrowhead) in the region of a regular intervertebral space (scale bar $=10 \mu \mathrm{m}$ ). (d) Regular notochord epithelium (black asterisk) and notochord sheath (white arrowhead) in the caudal region, prior to vertebral body formation. The elastic membrane that surrounds the notochord sheath is visible as thin dark line (black arrowhead). The white asterisks indicate cartilage (scale bar $=10 \mu \mathrm{m})$. (e) Alterations of the notochord sheath (white arrowhead), the notochord epithelium (black asterisk) and the inner notochord cells (white asterisk) in the region of vertebral body malformation (scale bar $=20 \mu \mathrm{m}$ ). Higher magnifications are given in $\mathrm{f}$ and g. (f) Dislocated matrix inside the notochord (white arrowheads) displays the same metachromatic staining as cartilage (white asterisk) (scale bar $=10 \mu \mathrm{m})$. (g) Previously highly vacuolated cells in the centre of the healthy notochord display small vacuoles, or vacuoles are absent (black arrowhead). Different from normal cells, cell nuclei move from the periphery of the notochord into the centre (black asterisk). Notice the intensive interdigitation of the cell membranes (white arrowhead) (scale bar $=10 \mu \mathrm{m}$ ). (h) Pathological thinning and fenestration of the notochord sheath (black arrowhead), located posterior to the centre of vertebral body malformation (scale bar $=10 \mu \mathrm{m}$ ). 
mortality rate. Our results demonstrate that notochord-related haemal lordosis could be identified during the early larval stage, in the form of abnormal developmental patterns of the cartilaginous neural and haemal processes and a disturbed pattern of notochord centrum mineralization.

\section{Acknowledgements}

We thank Dr E. Schismenou for her help in embedding specimens and to Mieke Soenens for sectioning and staining. Also, we thank the managers of the hatchery for the provision of the information about rearing methodology. This study was funded by the program NSRF 20072013, 'Competitiveness \& Entrepreneurship' (call Cooperation I, Project No 09SYN-24-619) of the Ministry of Education, Lifelong Learning and Religious Affairs, Greece. Mrs Georgiou A.N. holds a scholarship from European Union (European Social Fund - ESF) and Greek national funds through the Operational Program 'Education and Lifelong Learning' of the National Strategic Reference Framework (NSRF) - Research Funding Program: Heracleitus II, Investing in knowledge society through the European Social Fund.

\section{References}

Andrades J.A., Becerra J. \& Fernandez-Llebrez P. (1996) Skeletal deformities in larval, juvenile and adult stages of cultured gilthead sea bream (Sparus aurata L.). Aquaculture 141, 1-11.

Barahona-Fernandes M.H. (1982) Body deformation in hatchery reared European sea bass Dicentrarchus labrax (L.). Types, prevalence and effect on fish survival. Journal of Fish Biology 21, 239-249.

Bensimon-Brito A., Cancela M.L., Huysseune A. \& Witten P.E. (2012a) Vestiges, rudiments and fusion events: the zebrafish caudal fin endoskeleton in an evo-devo perspective. Evolution \& Development 14, 116-127.

Bensimon-Brito A., Cardeira J., Cancela M.L., Huysseune A. \& Witten P.E. (2012b) Distinct patterns of notochord mineralization in zebrafish coincide with the localization of Osteocalcin isoform 1 during early vertebral centra formation. BMC Developmental Biology 12, 28.

Boglione C. \& Costa C. (2011) Skeletal Deformities and Juvenile Quality. In: Sparidae, pp. 233-294. WileyBlackwell, Chichester, UK.

Boglione C., Gagliardi F., Scardi M. \& Cataudella S. (2001) Skeletal descriptors and quality assessment in larvae and post-larvae of wild-caught and hatchery-reared gilthead sea bream (Sparus aurata L. 1758). Aquaculture 192, $1-22$.
Boglione C., Costa C., Giganti M., Cecchetti M., Dato P.D., Scardi M. \& Cataudella S. (2006) Biological monitoring of wild thicklip grey mullet (Chelon labrosus), golden grey mullet (Liza aurata), thinlip mullet (Liza ramada) and flathead mullet (Mugil cephalus) (Pisces: Mugilidae) from different Adriatic sites: meristic counts and skeletal anomalies. Ecological Indicators 6, 712-732.

Boglione C., Gavaia P., Koumoundouros G., Gisbert E., Moren M., Fontagné S. \& Witten P.E. (2013a) A review on skeletal anomalies in reared European larvae and juveniles. Part 1: Normal and anomalous skeletogenic processes. Reviews in Aquaculture 5, S99-S120.

Boglione C., Gisbert E., Gavaia P., Witten P.E., Moren M., Fontagné S. \& Koumoundouros G. (2013b) Skeletal anomalies in reared European fish larvae and juveniles. Part 2: main typologies, occurrences and causative factors. Reviews in Aquaculture 5, S121-S167.

Chatain B. (1994) Abnormal swimbladder development and lordosis in sea bass (Dicentrarchus labrax) and sea bream (Sparus auratus). Aquaculture 119, 371-379.

Cobcroft J.M. \& Battaglene S.C. (2009) Jaw malformation in striped trumpeter Latris lineata larvae linked to walling behaviour and tank colour. Aquaculture 289, 274-282.

Cobcroft J.M. \& Battaglene S.C. (2013) Skeletal malformations in Australian marine finfish hatcheries. Aquaculture 396-399, 51-58.

Darias M.J., Mazurais D., Koumoundouros G., Glynatsi N., Christodoulopoulou S., Huelvan C., Desbruyeres E., Le Gall M.M., Quazuguel P., Cahu C.L. \& Zambonino-Infante J.L. (2010) Dietary vitamin D(3) affects digestive system ontogenesis and ossification in European sea bass (Dicentrachus labrax, Linnaeus, 1758). Aquaculture 298, 300-307.

De Azevedo T.P., Witten P.E., Huysseune A., Bensimon-Brito A., Winkler C., To T.T. \& Palmeirim I. (2012) Interrelationship and modularity of notochord and somites: a comparative view on zebrafish and chicken vertebral body development. Journal of Applied Ichthyology 28, 316-319.

Diggles B.K. (2013) Saddleback deformities in yellowfin bream, Acanthopagrus australis (Günther), from South East Queensland. Journal of Fish Diseases 36, 521-527.

Divanach P., Papandroulakis N., Anastasiadis P., Koumoundouros G. \& Kentouri M. (1997) Effect of water currents on the development of skeletal deformities in sea bass (Dicentrarchus labrax L.) with functional swimbladder during postlarval and nursery phase. Aquaculture 156, 145-155.

Faustino M. \& Power D.M. (1998) Development of osteological structures in the sea bream: vertebral column and caudal fin complex. Journal of Fish Biology 52, 11-22.

Fernandez I., Hontoria F., Ortiz-Delgado J.B., Kotzamanis Y., Estevez A., Zambonino-Infante J.L. \& Gisbert E. (2008) Larval performance and skeletal deformities in farmed gilthead sea bream (Sparus aurata) fed with graded levels of Vitamin A enriched rotifers (Brachionus plicatilis). Aquaculture 283, 102-115.

Fernández I., Ortiz-Delgado J.B., Sarasquete C. \& Gisbert E. (2012) Vitamin A effects on vertebral bone tissue homeostasis in gilthead sea bream (Sparus aurata) juveniles. Journal of Applied Ichthyology 28, 419-426. 
Fjelldal P.G., Hansen T., Breck O., Ørnsrud R., Lock E.J., Waagbø R., Wargelius A. \& Eckhard Witten P. (2012) Vertebral deformities in farmed Atlantic salmon (Salmo salar L.) - etiology and pathology. Journal of Applied Ichthyology 28, 433-440.

Georgakopoulou E., Angelopoulou A., Kaspiris P., Divanach P. \& Koumoundouros G. (2007) Temperature effects on cranial deformities in European sea bass, Dicentrarchus labrax (L.). Journal of Applied Ichthyology 23, 99-103.

Georgakopoulou E., Katharios P., Divanach P. \& Koumoundouros G. (2010) Effect of temperature on the development of skeletal deformities in Gilthead seabream (Sparus aurata Linnaeus, 1758). Aquaculture 308, 13-19.

Gorman K.F., Pohl K., Ali F., Bandwait K. \& Breden F. (2012) Model teleosts for the study of idiopathic-type spinal curvatures: potential biomedical applications. Journal of Applied Ichthyology 28, 353-359.

Grotmol S., Kryvi H. \& Totland G.K. (2005) Deformation of the notochord by pressure from the swim bladder may cause malformation of the vertebral column in cultured Atlantic cod Gadus morhua larvae: a case study. Diseases of Aquatic Organisms 65, 121-128.

Hall B.K. (1977) Chondrogenesis of the somitic mesoderm. Advances in anatomy, embryology, and cell biology 53, 3-47.

Hay O.P. (1895) On the structure and development of the vertebral column of Amia [by] O. P. Hay, Chicago.

Huxley T.H. (1859) Observations on the Development of some parts of the Skeleton of Fishes. Transactions of the Microscopical Society \& Journal 7, 33-46.

Izquierdo M.S., Scolamacchia M., Betancor M., Roo J., Caballero M.J., Terova G. \& Witten P.E. (2013) Effects of dietary DHA and $\alpha$-tocopherol on bone development, early mineralisation and oxidative stress in Sparus aurata (Linnaeus, 1758) larvae. British Journal of Nutrition 109, 1796-1805.

Jonasson K.A., Russell A.P. \& Vickaryous M.K. (2012) Histology and histochemistry of the gekkotan notochord and their bearing on the development of notochordal cartilage. Journal of Morphology 273, 596-603.

Kihara M., Ogata S., Kawano N., Kubota I. \& Yamaguchi R. (2002) Lordosis induction in juvenile red sea bream, Pagrus major, by high swimming activity. Aquaculture 212, 149-158.

Koumoundouros G. (2008) First record of saddleback syndrome in wild parrotfish Sparisoma cretense (L., 1758) (Perciformes, Scaridae). Journal of Fish Biology 72, 737-741.

Koumoundouros G. (2010) Morpho-anatomical abnormalities in Mediterranean marine aquaculture. In: Recent Advances in Aquaculture Research (ed. by G. Koumoundouros), pp. 125-148. Kerala, Transworld Research Network.

Koumoundouros G., Maingot E., Divanach P. \& Kentouri M. (2002) Kyphosis in reared sea bass (Dicentrarchus labrax L.): ontogeny and effects on mortality. Aquaculture 209, 49-58.

Kranenbarg S., Van Cleynenbreugel T., Schipper H. \& Van Leeuwen J. (2005) Adaptive bone formation in acellular vertebrae of sea bass (Dicentrarchus labrax L.). Journal of Experimental Biology 208, 3493-3502.

Mazurais D., Glynatsi N., Darias M.J., Christodoulopoulou S., Cahu C.L., Zambonino-Infante J.L. \& Koumoundouros G.
(2009) Optimal levels of dietary vitamin A for reduced deformity incidence during development of European sea bass larvae (Dicentrarchus labrax) depend on malformation type. Aquaculture 294, 262-270.

Polo A., Yufera M. \& Pascual E. (1991) Effects of temperature on egg and larval development on Sparus aurata L. Aquaculture 92, 367-375.

Renn J. \& Winkler C. (2012) Osterix:nlGFP transgenic medaka identify regulatory roles for retinoic acid signaling during osteoblast differentiation in vivo. Journal of Applied Ichthyology 28, 360-363.

Risbud M.V. \& Shapiro I.M. (2011) Notochordal cells in the adult intervertebral disc: new perspective on an old question. Critical Reviews in Eukaryotic Gene Expression 21, 29-41.

Rohlf F.J. (2008) tpsDig, version 2.12. Department of Ecology and Evolution, State University of New York, Stony Brook, NY.

Santamaria J.A., Andrades J.A., Herraez P., Fernandez-Llebrez P. \& Becerra J. (1994) Perinotochordal connective sheet of gilthead sea bream larvae (Sparus aurata, L.) affected by axial malformations: an histochemical and immunocytochemical study. Anatomical Record 240, 248-254.

Schultze H.-P. \& Arratia G. (1988) Reevaluation of the caudal skeleton of some actinopterygian fishes: II. Hiodon, Elops, and Albula. Journal of Morphology 195, 257-303.

Sfakianakis D.G., Georgakopoulou E., Papadakis I.E., Divanach P., Kentouri M. \& Koumoundouros G. (2006) Environmental determinants of haemal lordosis in European sea bass, Dicentrarchus Labrax (Linnaeus, 1758). Aquaculture 254, 54-64.

Sokal R.R. \& Rohlf F.J. (1981) Biometry: The Principles and Practice of Statistics in Biological Research. W.H, Freeman, New York.

To T.T., Witten P.E., Renn J., Bhattacharya D., Huysseune A. \& Winkler C. (2012) Rankl-induced osteoclastogenesis leads to loss of mineralization in a medaka osteoporosis model. Development 139, 141-150.

Walker M.B. \& Kimmel C.B. (2007) A two-color acid-free cartilage and bone stain for zebrafish larvae. Biotechnic \& Histochemistry 82, 23-28.

Willems B., Büttner A., Huysseune A., Renn J., Witten P.E. \& Winkler C. (2012) Conditional ablation of osteoblasts in medaka. Developmental Biology 364, 128-137.

Witten P.E., Gil-Martens L., Hall B.K., Huysseune A. \& Obach A. (2005) Compressed vertebrae in Atlantic salmon Salmo salar: evidence for metaplastic chondrogenesis as a skeletogenic response late in ontogeny. Diseases of Aquatic Organisms 64, 237-246.

Witten P.E., Obach A., Huysseune A. \& Baeverfjord G (2006) Vertebrae fusion in Atlantic salmon (Salmo salar): development, aggravation and pathways of containment. Aquaculture 258, 164-172.

Zhou S.L., Dong Q.X., Li S.N., Gu J.F., Wang X.X. \& Zhu G.N.A. (2009) Developmental toxicity of cartap on zebrafish embryos. Aquatic Toxicology 95, 339-346.

Received: 29 June 2013

Revision received: 28 August 2013

Accepted: 30 August 2013 